IZA DP No. 5069

The Effect of Part-Time Work on

Post-Secondary Educational Attainment:

New Evidence from French Data

Magali Beffy

Denis Fougère

Arnaud Maurel

July 2010 


\title{
The Effect of Part-Time Work on Post-Secondary Educational Attainment: New Evidence from French Data
}

\author{
Magali Beffy \\ INSEE and CREST
}

Denis Fougère

CNRS, CREST, DEPP, CEPR and IZA

\author{
Arnaud Maurel \\ CREST, ENSAE, PSE \\ and IZA
}

Discussion Paper No. 5069

July 2010

IZA

P.O. Box 7240

53072 Bonn

Germany

Phone: +49-228-3894-0

Fax: +49-228-3894-180

E-mail: iza@iza.org

Any opinions expressed here are those of the author(s) and not those of IZA. Research published in this series may include views on policy, but the institute itself takes no institutional policy positions.

The Institute for the Study of Labor (IZA) in Bonn is a local and virtual international research center and a place of communication between science, politics and business. IZA is an independent nonprofit organization supported by Deutsche Post Foundation. The center is associated with the University of Bonn and offers a stimulating research environment through its international network, workshops and conferences, data service, project support, research visits and doctoral program. IZA engages in (i) original and internationally competitive research in all fields of labor economics, (ii) development of policy concepts, and (iii) dissemination of research results and concepts to the interested public.

IZA Discussion Papers often represent preliminary work and are circulated to encourage discussion. Citation of such a paper should account for its provisional character. A revised version may be available directly from the author. 


\section{ABSTRACT \\ The Effect of Part-Time Work on Post-Secondary Educational Attainment: New Evidence from French Data*}

In this paper, we provide new evidence on the effect of part-time work on postsecondary educational attainment. To do so, we use samples extracted from the French Labor Force Surveys conducted over the years 1992-2002. These samples are restricted to students in initial education following university studies and preparing an Associate, a Bachelor or a Master degree. We estimate probit models with two simultaneous equations accounting for part-time working while studying and for success on the final exam, along with the decision to continue the following year in one of the models. We take the working time into account by drawing in one of the models a distinction between jobs in which more or less than 16 hours are worked per week. We use variations across departements in low-skilled youth unemployment rates and in their interactions with the father's socio-economic status in order to identify the effect of part-time work on educational attainment. Our results suggest a statistically significant and very large detrimental effect of holding a regular part-time job on graduation probability. Still, a complementary analysis shows that working while studying does not have any significant effect on the probability of continuing studies.

\section{NON-TECHNICAL SUMMARY}

The findings reported in this article suggest that working while studying significantly reduces the probability of passing the university year-end exam. Our estimates show that this detrimental effect is very large, with the average probability of success of working students being about 43 points higher if they did not work. From a policy point of view, taxation reforms giving students an incentive to increase the number of hours worked, which are currently discussed in France, might therefore have a perverse effect by indirectly leading to a rise in the rate of failure at university exams. The problem is all the more acute as our results suggest that the detrimental effect of part-time work on educational attainment is especially strong in the French university system, in which evening classes and continuous assessment of students are quite uncommon.

JEL Classification: $\quad$ C35, I20, J24

Keywords: post-secondary educational attainment, students' labor supply, bivariate Probit models

Corresponding author:

Arnaud Maurel

ENSAE

Bureau E12 - Timbre J120

3, Avenue Pierre Larousse

92245 Malakoff cedex

France

E-mail: maurel@ensae.fr

\footnotetext{
* We thank Peter Arcidiacono, Elise Coudin, Fabrice Etilé, Xavier d'Haultfoeuille, Marc Gurgand, Sabrina Pabilonia, Thomas Piketty, Jean-Baptiste Pomarède, Jean-Marc Robin, Chloé Tavan and participants in various seminars for very helpful discussions and comments.
} 


\section{Introduction}

The higher education situation in France has been the subject of much debate, covering the effects of the twofold separation between the so-called Grandes Ecoles (élite schools) and universities on the one hand, and teaching and research, on the other hand, as well as the scarce resources allocated to higher education. ${ }^{1}$ However, one of the most worrisome characteristics of the French higher education system is the especially high university dropout rate. According to the French Ministry of Education, during the academic year 2006-2007, more than a quarter of students enrolled in their first year of university studies in France do not enroll again in the following year. An increase in the number of students who work to finance their studies is often mentioned as one of the possible causes of these frequent dropouts. According to the report of the French Conseil Economique et Social on students' employment (2007), $15 \%$ to $20 \%$ of students work regularly while studying. This proportion of working students increased quite significantly during the 1990s, rising by 4.4 points between 1990 and 2002, but has flattened out since then.

In this paper, we investigate the effect of part-time work on post-secondary attainment, as

\footnotetext{
${ }^{1}$ The French higher education system is composed of universities, grandes écoles, and specialized schools. Universities are public institutions which offer academic, technical, and professional degrees to any student who has achieved a French baccalauréat (the high-school final diploma) or a foreign equivalent. University study can lead to various types of degrees in many fields. Degrees are awarded at three different levels of achievement, called cycles, within a framework referred to as licence, master, doctorat (L-M-D), which is described below. Grandes écoles are prestigious public and private institutions that are highly selective. They are similar to universities but generally offer a more specialized three-year course of study, such as business, public administration, or engineering. Students are admitted to grandes écoles based on their scores on a competitive exam. The exam is open to students who hold a baccalauréat and who have taken the two-year preparatory course. Students graduate from a grande école with a Master degree. The university system in France has historically been divided into three cycles. The first cycle (baccalauréat plus 2 years of study), which corresponds to college in the U.S., leads to a DEUG degree. The second cycle (baccalauréat plus 3-4 years of study) leads to a licence (a Bachelor degree) after the first year and a maîtrise (a Master degree) after the second. The third cycle (baccalauréat plus $5+$ years of study) consists of either professional studies leading to a DESS or academic studies leading to a DEA and possibly a doctorat. This three cycle system of higher education is being replaced by the L-M-D. The L-M-D system is a relatively new effort to harmonize degree qualifications in France with the rest of Europe. The degrees awarded under the old system will continue to be offered to students who wish to pursue them, but many professional degrees awarded after five years of post-secondary will be eliminated in favor of the Master degree. The new L-M-D system is also divided into three cycles. However, the first cycle now lasts for three years instead of two and leads to a licence. The second cycle lasts for two years and results in a Master degree. The DESS and DEA now fit in the 2nd cycle. The third cycle leads to a Doctorat.
} 
measured by graduation and continuation. ${ }^{2}$ Providing additional evidence on the impact of part-time work on post-secondary educational attainment seems especially worthwhile since the existing empirical literature focuses mainly on the effects of part-time working while enrolled in high school. Somewhat paradoxically, although the incidence of part-time work is higher in college than in high school, little is known about the impact of part-time work on college degree attainment. This article constitutes one of the first attempt to estimate the effect of part-time work both on college graduation and continuation, relying on data from a nationally-representative survey. ${ }^{3}$ Recently, Kalenkoski \& Pabilonia (2010) have used representative data to estimate the effect of part-time work on post-secondary academic achievement. Nevertheless, these authors only consider the impact of part-time work on grade point averages by the end of the first college term, but their identification strategy breaks down for four-year college students. Our article is also the first empirical study to deal with this issue in France. For that purpose, we use samples drawn from the French Labor Force Surveys conducted by the National Institute of Statistics and Economic Studies (INSEE, Paris) over the years 1992-2002. These samples are restricted to students in initial education following university studies and preparing an associate, a bachelor or a master degree. We exclude from our analysis students enrolled in vocational tracks. The main difficulty in identifying the causal effect of part-time work on academic attainment stems from the potential endogeneity of part-time labor supply. Indeed, the decision to work while in school is likely to be related to unobserved characteristics that are also related to academic attainment. For instance, students working part-time may on average have either a lower or a higher unobserved ability or motivation for schooling. In such a case, OLS estimates of the effect of part-time work would be biased. In order to cope with this issue, we rely on an instrumental variable strategy. Namely, similarly to Dustmann \& van Soest (2007) and Montmarquette et al. (2007), we use variations in students' part-time labor supply induced by the local unemployment rates (at the level of the département, which corresponds roughly to an U.S. county), computed for individuals under 29 with a secondary schooling level. This local unemployment variable, which is arguably exogenous with respect to academic attainment, is used as a proxy for local labor market conditions which are faced by the students deciding to work part-time while studying. Our identifica-

\footnotetext{
${ }^{2}$ In the paper, continuation corresponds to the situation where a student stays in education the following year.

${ }^{3}$ On a related ground, a paper by Ehrenberg \& Sherman (1987) considered the effect of part-time working while enrolled in college on grade point averages, on the probability of staying on in education and on postcollege outcomes. Nevertheless, they restricted their analysis to a subsample of male high school graduates.
} 
tion strategy also exploits the interactions between the local unemployment rate and the father's socio-economic status. The underlying idea for the use of this latter instrument is that the width of the social and professional network of the parents is likely to limit the negative impact of unfavorable economic conditions on the probability of finding a part-time job (see Kramarz \& Skans, 2007).

In order to estimate the effect of part-time work on academic attainment, we estimate probit models with two simultaneous equations accounting for part-time working while studying and for success on the final exam, along with the decision to continue the following year in one of the models. We take the working time into account by making a distinction between jobs in which more or less than 16 hours are worked per week. ${ }^{4}$ Using the parameter estimates, we can compute the average effect of part-time work on the graduation probability, which is further decomposed by major and by level of studies. Overall, our results suggest a statistically significant and very large detrimental effect of working part-time on the probability of passing the final exam. Compared to prior evidence available from North American and British data, our estimates suggest a strong negative impact of part-time work on academic achievement. We argue that this finding may be due to the lack of flexibility of the French university system, which does not offer much complementarities between schooling achievement and part-time work. Our results also highlight the need to take the endogeneity of part-time labor supply into account since simple probit estimates strongly underestimate the detrimental effect of part-time work. Finally, a complementary analysis suggests that, despite its strong negative effect on the graduation probability, working part-time does not have any significant effect on the probability to stay on in post-secondary education. The remainder of the paper is organized as follows. Section 2 reviews the existing empirical literature about the effect of part-time work on academic attainment. Section 3 describes the data. Section 4 is devoted to the impact of part-time work on the graduation probability, while Section 5 deals with the effect of working part-time on the probability to continue the following year. Finally Section 6 concludes.

\footnotetext{
${ }^{4}$ The cutoff is set at 16 hours per week consistently with the existing literature, which suggests that working more than a certain number of hours, usually between 10 and 20 hours per week, is especially detrimental to educational attainment. Descriptive evidence from our data suggests that the related break indeed occurs around 16 hours per week.
} 


\section{A summary of previous findings}

Many studies have been devoted to the situation where part-time work and studies are combined, and in particular to the effects of working while studying on academic performance and on the decision to stay on in education. However, there is still no consensus whether holding a part-time job while studying has a substantial detrimental effect on academic attainment.

A first generation of papers has focused on the relationship between part-time working and educational attainment and primarily examined correlations as well as OLS estimates. Some of these articles found that working part-time while studying has no significant detrimental effect on academic attainment (Gade \& Peterson, 1980; Meyer \& Wise, 1982; Steinberg et al., 1982; D'Amico, 1984; Hotchkiss, 1986). Others concluded to a negative relationship between working part-time and academic achievement (Greenberger et al., 1980; Marsh, 1991). Many articles actually showed that the effects vary, according to the number of hours worked. These papers concluded to a non-linear relationship between the number of hours worked and academic achievement. When the number of hours worked per week is low, they find a non-negative and sometimes positive effect of part-time work on educational performance (D'Amico, 1984; Schill et al., 1985; Steel, 1991), while holding a regular and intensive job is found to significantly lower students' chances of success (Schill et al., 1985; Steel, 1991).

However, as the decision to work part-time while studying can be endogenous, simple OLS estimates of the effect of part-time work on academic attainment are likely to be biased. Ehrenberg \& Sherman (1987) were the first to tackle this endogeneity issue. Relying on an instrumental variable approach, they found that part-time working has no significant effect on grades. Conversely, they found a significant adverse effect on the probability of staying-on in education. Lillydahl (1990) took into consideration the potential endogeneity of part-time work in a similar way. The author came to the conclusion that there is a nonlinear effect of the number of hours worked on results at standardized SAT tests: while working less than 13 hours and a half per week has a positive effect on test scores, working more than 13 hours and a half has a negative effect.

More recently, Oettinger (1999) also stressed that one needs to take into account the endogeneity of students' work. Exploiting the longitudinal dimension of data extracted from the NLSY-79 (National Longitudinal Survey of Youth) by estimating fixed-effect models, this author concludes to a very small detrimental effect of part-time work on high-school 
achievement. ${ }^{5}$ Stinebrickner \& Stinebrickner (2003) showed that different estimation methods of the effect of part-time work on college degree attainment (namely OLS, 2SLS, and linear panel models with fixed effects) led to significantly different results, thus highlighting once again the need to take into account the endogeneity issue. ${ }^{6}$ Tyler (2003) uses an original instrumental strategy in order to identify the causal effect of combining working and studying on academic achievement at the level of high schools. Taking advantage of differences between child labor laws across U.S. states, Tyler found a significant detrimental effect of part-time work on twelfth-grade achievement. His results also suggest that OLS underestimate the negative impact of working part-time while studying. Rothstein (2007) and Buscha et al. (2008) use the panel dimension of data extracted from the NLSY-97 and the NELS:88 (National Education Longitudinal Study) with fixed-effects estimators and difference-in-differences methods combined with propensity score matching, respectively. These two papers conclude to a non significant effect of working while studying on high-school achievement. More recently, Kalenkoski \& Pabilonia (2010) use data from the NLSY-97 to estimate the effect of working part-time on academic performance in college. Using the net price of schooling and the local unemployment rate as instruments for the number of hours worked, they conclude that there is a significantly negative effect of working while in college on grade point averages. ${ }^{7}$

Other studies rely on a more structural approach. Using the NLSY-79, Eckstein \& Wolpin (1999) estimate a dynamic structural model of high school attendance and part-time work decisions. Their model is based on the assumption that the effort made by high-school students during their studies varies in the opposite direction to their labor supply. By simulating the impact of public policies curtailing the possibilities of combining work and study, Eckstein and Wolpin conclude to a negative, albeit quantitatively weak, effect of working while studying on high-school achievement. ${ }^{8}$

\footnotetext{
${ }^{5}$ Aside from the papers considering the effect of part-time work on academic attainment, several articles focus on its longer-term effects on labor market outcomes. Relying on the same dataset (NLSY-79), papers by Ruhm (1997) and Light (1999) suggest positive wage returns to working part-time in high-school, while Hotz et al. (2002) conclude to non-significant wage returns to working part-time in high school or college. Dealing with the endogeneity of part-time work is also a major issue in this strand of the literature.

${ }^{6}$ Most existing studies look into the effect of part-time work on high-school attainment. Among the articles presented in this literature review, Ehrenberg \& Sherman (1987), Stinebrickner \& Stinebrickner (2003) and Kalenkoski \& Pabilonia (2010) are the only ones to consider the effect of part-time work on university level achievement.

${ }^{7}$ An original feature of the model estimated in Kalenkoski \& Pabilonia (2010) lies in the fact that the parental financial transfer is an endogenous determinant of students' part-time labor supply.

${ }^{8}$ According to their estimates, if high school students could not work part-time, the success rate at the high school diploma would improve only from $82 \%$ to $84.1 \%$.
} 
Finally, a few articles study the impact of part-time employment both on educational performance and on the decision to stay on in education. This is the case in particular of the study by Eckstein \& Wolpin (1999) who estimate the impact of part-time work on the continuation rate. Montmarquette et al. (2007) also estimate the effect of parttime work on school performance as well as on the probability to drop-out. They show that, for Canadian high school students, an intensive regular job (more than 30 hours per week) significantly reduces the probabilities of performing well at school and staying-on in education. Conversely, working very few hours per week (less than 15) has a small, actually non-significant impact on school performance and on the probability of dropping out. Finally, using British data, Dustmann \& van Soest (2007) estimate a model with three simultaneous equations accounting for part-time labor supply, school performance and for the decision to drop-out. The authors conclude to a negative effect, albeit fairly weak, of student work on school performance as well as on the decision to stay on in education beyond the minimum age for leaving the educational system. These last two articles use variations in the local unemployment rate as well as in the level of parental education in order to identify the impact of working on school performance and on the decision to stay on in education.

\section{Data and identification strategy}

The data we use are extracted from the annual Labor Force Surveys (LFS) conducted each year by the French National Institute of Statistics and Economic Studies (INSEE) from 1992 to 2002. The French LFS is a rotating nationally-representative panel in which households are surveyed for three consecutive years. Our sample is built as follows: for any year $t$ ranging between 1992 and 2001, we select students belonging to households interviewed for the first time, who were enrolled in university studies for initial education, and who were preparing an associate, a bachelor or a master degree. Only students who also answered the survey in year $t+1$ were kept. We also restrict our sample to those who were younger than 29 in year $t$ and who were born in mainland France. Furthermore, we exclud students following a course combining work and studies: this category comprises apprentices under contract as well as medical interns. The determinants of this kind of part-time work are indeed not the same. We are finally left with a sample of 1,603 students. ${ }^{9}$

\footnotetext{
${ }^{9}$ Note that this sample does not provide findings concerning students who changed their residence between years $t$ and $t+1$ since the LFS samples housing units and not individuals. Similarly, our results cannot be generalized to students who are not following a university course. Note, however, that the
} 
The employment variable we choose corresponds to the individual situation with respect to the labor force at the date of the survey (i.e. in March), as defined by the International Labor Organization. We allow the probability to work part-time while studying to depend on the level of studies currently followed and on the field of studies, two dummy variables taking the value 1 (0 otherwise) when the student's age is either one year or at least two years above the usual age in the schooling level under consideration (this usual age being 20 years old or younger for an associate degree, 21 years old or younger for a bachelor degree, and 22 years old or younger for a master degree), dummies for gender, matrimonial status, a dummy for residence in the Paris region, the number of individuals and the presence of children aged 18 or younger in the household. ${ }^{10}$ Finally, we also control for year-specific effects.

We also rely on instrumental variables that are supposed to affect the graduation probability only through part-time work. These variables ensure the identification of the models we estimate. They include the unemployment rate in the département for low-skilled individuals aged 15 to $29,{ }^{11}$ the father's social status ${ }^{12}$ and its interaction with the local unemployment rate.

The father's socio-economic status is likely to be correlated with the parental income, which is not observed in the data. Students whose father has a higher social status are more likely to work less often to finance their studies, because of the higher level of financial support they can benefit from. Besides, although some empirical evidence suggests that the parental socio-economic status has an impact on primary and secondary schooling attainment, there is no clear reason why the father's socio-economic status should still have a direct effect on

dropout rate is particularly high in French universities, and in this respect it seems relevant to restrict our sample to students enrolled in universities.

${ }^{10}$ In this case, it is the household the student belongs to. In fact, the dummy for residence in the Paris region, the number of individuals and the presence of children aged 18 or younger in the household, do not have a statistically significant effect on the probability of passing the year-end exam, but they do have one on the propensity to work part-time. These variables are therefore excluded from the equation accounting for success at the exam, but are introduced into the employment equation. Therefore, they contribute to the overidentification of our models.

${ }^{11}$ Low-skilled youth corresponds to individuals with a high-school educational level. For all individuals in the sample, this local unemployment variable was computed from the 1990 and 1999 French Censuses as the average of the local unemployment rates in years 1990 and 1999. We use the spatial variation in local unemployment rate to identify the effect of part-time work on graduation and continuation of studies.

${ }^{12}$ This variable is binary. The first value corresponds to the highest socio-economic status, which includes managers of companies with 10 employees or more, professionals, administrative and business managers of companies, as well as engineers and technical managers of companies. The second category includes all other socio-economic status, in particular intermediate occupations, blue-collar and white-collar workers. 
academic performance in post-secondary education. Nevertheless we discuss more in detail in Section 4 the validity of this exclusion restriction, with robustness checks exploiting in particular the fact that we are in an overidentified setting. The unemployment rate of low-skilled youth in the département is an indicator of the problems faced by students deciding to work part-time while studying. Indeed, working students are often employed in low-skilled jobs, notably in retail trade and the hotel-catering sector. Hence, when the local unemployment rate of low-skilled youth is high, these jobs in services will be less frequent, which will in turn lower the probability to work part-time while studying. Figure 1 below reports the relationships between the deciles of the local low-skilled youth unemployment rate and the part-time employment rates observed in the sample, and between these deciles and the sample graduation rates.

Figure 1: Part-time employment and graduation rates according to the deciles of the local unemployment rate for low-skilled workers

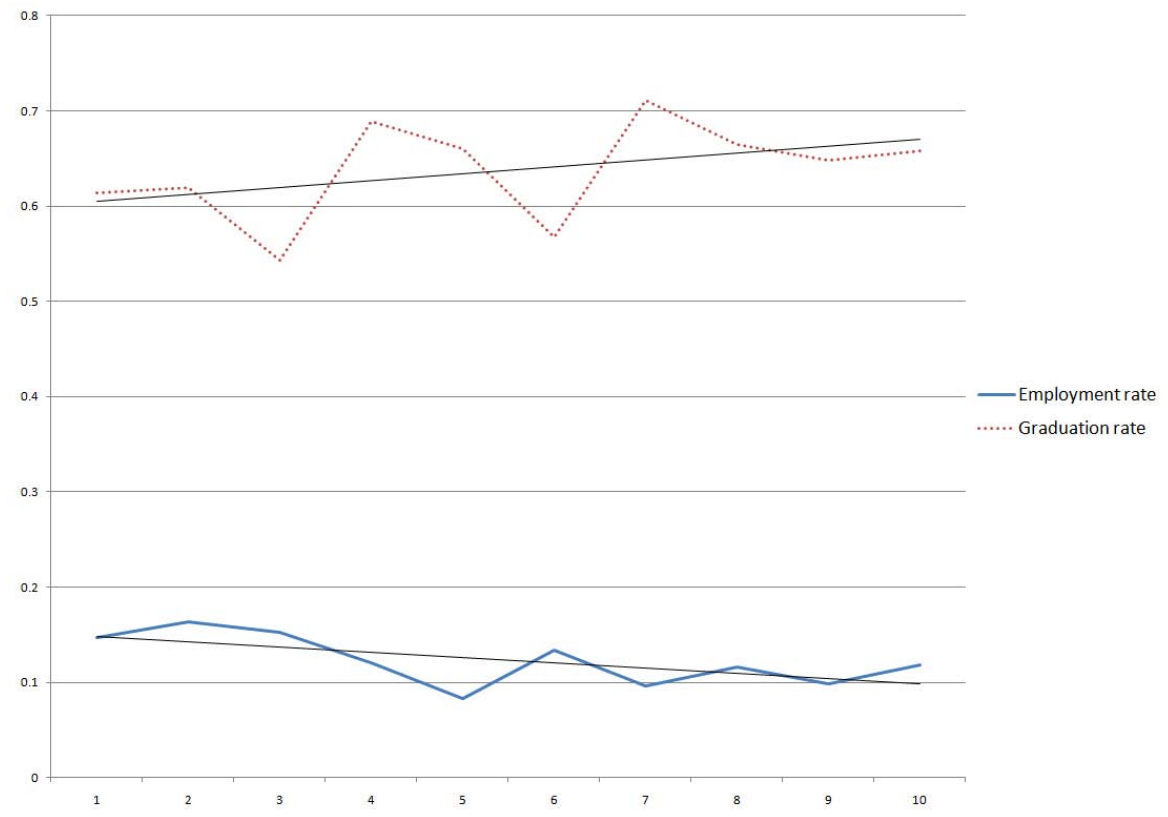

From a descriptive point of view, this figure suggests that there is indeed in the data a slightly negative relationship between the local unemployment rate for low-skilled workers under 29 and the students' part-time employment rate, which is consistent with the kind of mechanism discussed above. ${ }^{13}$ As shown in the sequel, this negative relationship, which is characterized here by an estimate of the correlation coefficient which is statistically

\footnotetext{
${ }^{13}$ The deciles of the local unemployment rate for low-skilled workers under 29, averaged over the period $1990-1999$, are equal to $16.2 \%, 17.3 \%, 18 \%, 19.9 \%, 20.7 \%, 21.5 \%, 23.6 \%, 25.4 \%, 28.7 \%$ and $32.7 \%$.
} 
significant at the $10 \%$ level only, is actually strengthened when controlling for other characteristics affecting the probability to hold a part-time job. Conversely, there is no clear reason why the local unemployment rate of low-skilled job seekers should have any direct effect on individual probabilities of being successful at university exams. ${ }^{14}$ Nevertheless, a concern about the validity of this instrument could be that students living in départements where the local unemployment rate is higher have on average a lower motivation for academic achievement. In such a case, our identification strategy could lead to underestimate the detrimental effect of holding a part-time job on academic achievement. We address this concern in Section 4 by including a proxy for students' motivation for schooling in the set of regressors. Our results are robust to this additional specification. We use the positive relationship, illustrated in Figure 1, between the local low-skilled unemployment rate and the graduation rate in order to identify the causal effect of part-time work on academic attainment.

Furthermore, several studies have shown that the socio-economic status of parents, an indirect measure of their income but also of the width of their network of social relationships, facilitates the access of youth to jobs, in particular when unemployment is high (see, in particular, Kramarz \& Skans, 2007). This is why we introduce an interaction between the socio-economic status of the student's father and the local unemployment rate of low-skilled youth, as the detrimental effect of the unemployment rate could be lower for students whose father has a higher socio-economic status. Finally, the exogenous variables which are used to explain graduation, include all the previous variables, apart from the instrumental variables.

In the complementary analysis of the effect of working part-time on the probability to stay on in education, the variables excluded from the academic attainment equation accounting both for graduation and continuation are the local unemployment rate of low-skilled workers aged 15 to 29 , as well as the interaction between the father's socal status and the unemployment rate. Unlike in the preceding specification, the overall local unemployment rate is used to explain graduation and continuation, but it is excluded from the employment equation.

The sample is composed of 1,603 individuals, 202 of whom work part-time while studying. The graduation rate stands at $63.4 \%$ in the whole sample, while it is equal to $66 \%$ for

\footnotetext{
${ }^{14}$ This hypothesis, and the exclusion restriction it results in, are also drawn upon by Dustmann \& van Soest (2007) and Montmarquette et al. (2007). The latter also use changes in the level of the real minimum wage to identify the effect of combining working and studying on the student's success. Probably due to its relatively small fluctuations in France during the period of interest, the level of the real hourly minimum wage is found here to have no significant effect on the probability of working while studying.
} 
students who do not work and $45.5 \%$ for working students. Among the 202 students who hold a job, 86 students work less than 16 hours per week and 116 work 16 hours or more. The average graduation rate stands at $55.8 \%$ for students who work less than 16 hours per week, and $37.9 \%$ for those who work 16 hours or more, respectively. ${ }^{15}$ Furthermore, in the whole sample, $88.5 \%$ of students continue their studies the following year. ${ }^{16}$ The proportion of students who stay on in education is $89.9 \%$ for students who do not work and $79.2 \%$ for those who do. In particular, $86.1 \%$ of students who work less than 16 hours, but only $74.1 \%$ of students who work 16 hours per week or more, stay on in education.

Table 1: Descriptive statistics (percentages)

\begin{tabular}{l|c|c|c} 
& Proportion & Success & Enrollment in year $t+1$ \\
\hline Working students (16 hours or more) & 7.2 & 37.9 & 74.1 \\
Working students (less than 16 hours) & 5.4 & 55.8 & 86.1 \\
Non working students & 87.4 & 66 & 89.9 \\
\hline Total & 100 & 63.4 & 88.5
\end{tabular}

\section{The impact of part-time work on graduation probability}

In this section, we seek to estimate the effect of part-time work on success on the year-end exam. To do so, we first rely on a bivariate probit model with structural shift (Heckman, 1978) and subsequently on a model that takes into account the number of hours worked per week.

\subsection{A bivariate probit model}

We first estimate a probit model with two equations. The first equation accounts for parttime working while studying, while the second one accounts for success in the final exam. So far, the decision to stay on in education, as well as the one to repeat the academic year

\footnotetext{
${ }^{15}$ The number of hours worked corresponds to the usual number of hours of work per week. For students who state they do not have a fixed working time, we use the number of hours worked in the week prior to the interview.

${ }^{16}$ Note that among the respondents who stay on in education, $34.6 \%$ do so after failing the final exam and repeat the year, while $65.4 \%$ are accepted to the following year.
} 
in the case of failing the exam, are not taken into account.

The student works part-time while studying (in which case $Y_{1}=1, Y_{1}=0$ otherwise) if the latent variable $Y_{1}^{*}$, defined by the equation $Y_{1}^{*}=X_{1} \beta_{1}+\varepsilon_{1}$, is positive. This latent variable can be interpreted as the individual propensity to combine working and studying. It depends on a set of individual characteristics $X_{1}$ and on a random term $\varepsilon_{1}$, which is supposed to follow a standard normal distribution $\mathcal{N}(0,1)$.

Success in the final exam is supposed to be determined by a latent variable $Y_{2}^{*}$ that is positive if the student graduates at the end of the academic year (in this case, $Y_{2}=1$ ), negative otherwise (in which case $Y_{2}=0$ ). This individual propensity to succeed, that can be interpreted as the difference between the individual score and the score corresponding to the average of grades ensuring the student passes the exam, is defined by a linear equation $Y_{2}^{*}=Y_{1} \beta_{20}+X_{2} \beta_{21}+\varepsilon_{2}$. This propensity is therefore supposed to depend first on the dummy variable for part-time work $\left(Y_{1}\right)$, which is a potentially endogenous variable, but also on a vector $X_{2}$ of individual characteristics, such as the major of studies, gender, etc. The random term $\varepsilon_{2}$ is once again supposed to follow a normal standard distribution $\mathcal{N}(0,1)$, and it is allowed to be correlated with the residual $\varepsilon_{1}$ of the graduation equation. Specifically, we denote $\sigma_{12}$ the covariance (here equal to the correlation coefficient) between the residuals. In other words, $\left(\varepsilon_{1}, \varepsilon_{2}\right)$ follows a normal bivariate distribution $\mathcal{N}(0, \Sigma)$ whose covariance matrix $\Sigma$ is equal to: ${ }^{17}$

$$
\Sigma=\left(\begin{array}{cc}
1 & \sigma_{12} \\
\sigma_{12} & 1
\end{array}\right)
$$

Note that if the covariance $\sigma_{12}$ is equal to zero, then the dummy variable for part-time work $Y_{1}$ is exogenous in the success equation, and the maximum likelihood estimation of this single equation yields consistent estimates of parameters $\beta_{2}=\left(\beta_{20}, \beta_{21}\right)^{\prime}$. Otherwise, $Y_{1}$ is endogenous and the separate estimation of the success equation yields biased estimates of $\beta_{2}$. The two equations then have to be simultaneously estimated.

The sample is divided into four sub-groups: $I_{1}$ refers to the individuals who do not work and who fail the exam $\left(Y_{1}=0\right.$ and $\left.Y_{2}=0\right), I_{2}$ refers to the individuals who do not work and pass the exam $\left(Y_{1}=0\right.$ and $\left.Y_{2}=1\right), I_{3}$ refers to the individuals who work and who fail the exam $\left(Y_{1}=1\right.$ and $\left.Y_{2}=0\right)$, and finally $I_{4}$ refers to the individuals who work and pass the exam $\left(Y_{1}=1\right.$ and $\left.Y_{2}=1\right)$.

We denote $\Phi_{2}\left(., ., \sigma_{12}\right)$ the cumulative distribution function of the normal bivariate distribution $\mathcal{N}(0, \Sigma)$. The contribution to the likelihood of the individual $i$ in the sample of size

\footnotetext{
${ }^{17}$ Probit models are identified up to a scaling factor, hence the normalization to the unit of the variance of residuals.
} 
$n(i=1, \ldots, n)$, denoted $P_{k i}$ (with $k=1, \ldots, 4$ indexing the sub-group), can therefore take four values:

$$
\begin{aligned}
& i \in I_{1} \Rightarrow P_{1 i}=\Phi_{2}\left(-X_{1 i} \beta_{1},-X_{2 i} \beta_{21}, \sigma_{12}\right) \\
& i \in I_{2} \Rightarrow P_{2 i}=\Phi_{2}\left(-X_{1 i} \beta_{1}, X_{2 i} \beta_{21},-\sigma_{12}\right) \\
& i \in I_{3} \Rightarrow P_{3 i}=\Phi_{2}\left(X_{1 i} \beta_{1},-\beta_{20}-X_{2 i} \beta_{21},-\sigma_{12}\right) \\
& i \in I_{4} \Rightarrow P_{4 i}=\Phi_{2}\left(X_{1 i} \beta_{1}, \beta_{20}+X_{2 i} \beta_{21}, \sigma_{12}\right)
\end{aligned}
$$

The log-likelihood of the model is then expressed as follows:

$$
\ln L=\sum_{i \in I_{1}} \ln P_{1 i}+\sum_{i \in I_{2}} \ln P_{2 i}+\sum_{i \in I_{3}} \ln P_{3 i}+\sum_{i \in I_{4}} \ln P_{4 i}
$$

\subsection{A model accounting for the number of working hours}

The second model extends the analysis by considering the number of hours worked each week. The first equation of the model now determines a variable $Y_{1}$ that takes three values, depending on whether the student does not work $\left(Y_{1}=0\right)$, works less than 16 hours per week $\left(Y_{1}=1\right)$, or works 16 hours or more per week $\left(Y_{1}=2\right)$. The second equation still accounts for success on the final exam. However, the working time $Y_{1}$ is now included in the list of explanatory variables of success at the exam with two dummy variables, according to whether working time is positive, but below or above 16 hours per week. The residuals of the two equations are once more potentially correlated, in order to account for the potential endogeneity of part-time labor supply.

Part-time work is now modeled with an ordered probit specification of the following form:

$$
\forall k \in\{0,1,2\}, \quad Y_{1}=k \Leftrightarrow s_{k}<Y_{1}^{*}=X_{1} \beta_{1}+\varepsilon_{1} \leq s_{k+1}
$$

where $Y_{1}^{*}$ refers to the individual propensity to work and $Y_{1}$ is a discrete variable taking three values that describe the amount of the student's working time. We denote hereafter $Y_{1}^{1}$ and $Y_{1}^{2}$ the dummy variables for working respectively less or more than 16 hours per week. When the propensity to work part-time is low, i.e. when it is formally lower than the threshold $s_{1}\left(s_{0}=-\infty<Y_{1}^{*} \leq s_{1}\right)$, the student does not work part-time, and in this case $Y_{1}=0$. When this propensity reaches an intermediate level, i.e. when its value ranges between the thresholds $s_{1}$ and $s_{2}\left(s_{1}<Y_{1}^{*} \leq s_{2}\right)$, the student works less than 16 hours per week, and in this case $Y_{1}=1$. Finally, when the individual propensity to work is higher than the threshold $s_{2}\left(s_{2}<Y_{1}^{*}<s_{3}=+\infty\right)$, the student works 16 hours or more per week, and in this case $Y_{1}=2$. The thresholds $s_{1}$ and $s_{2}$ are unknown and have to be estimated. 
In order to identify the model, we normalize the intercept to zero and the variance of the residual $\varepsilon_{1}$ to one. ${ }^{18}$

Success in the final exam is denoted as above by the binary variable $Y_{2}$, whose realization ( 0 in the case of a failure, 1 in the case of a success) is generated by the value of the latent propensity $Y_{2}^{*}=Y_{1}^{1} \beta_{20}^{1}+Y_{1}^{2} \beta_{20}^{2}+X_{2} \beta_{21}+\varepsilon_{2}$. $\varepsilon_{1}$ and $\varepsilon_{2}$ being once again supposed to follow a standard bivariate distribution $\mathcal{N}(0, \Sigma)$.

We denote $I_{1}$ the subsample of students who fail the exam and $I_{2}$ the subsample of students who pass the exam. For any observation in $I_{1}$, the individual contribution to the likelihood is written: ${ }^{19}$

$$
\begin{aligned}
P_{1}= & \Phi_{2}\left(s_{Y_{1}+1}-X_{1} \beta_{1},-Y_{1}^{1} \beta_{20}^{1}-Y_{1}^{2} \beta_{20}^{2}-X_{2} \beta_{21}, \sigma_{12}\right) \\
& -\Phi_{2}\left(s_{Y_{1}}-X_{1} \beta_{1},-Y_{1}^{1} \beta_{20}^{1}-Y_{1}^{2} \beta_{20}^{2}-X_{2} \beta_{21}, \sigma_{12}\right)
\end{aligned}
$$

Likewise, the contribution to the likelihood of an observation of subsample $I_{2}$ is written:

$$
\begin{aligned}
P_{2}= & \Phi_{2}\left(s_{Y_{1}+1}-X_{1} \beta_{1}, Y_{1}^{1} \beta_{20}^{1}+Y_{1}^{2} \beta_{20}^{2}+X_{2} \beta_{21},-\sigma_{12}\right) \\
& -\Phi_{2}\left(s_{Y_{1}}-X_{1} \beta_{1}, Y_{1}^{1} \beta_{20}^{1}+Y_{1}^{2} \beta_{20}^{2}+X_{2} \beta_{21},-\sigma_{12}\right)
\end{aligned}
$$

The log-likelihood of the whole sample is then written:

$$
\ln L=\sum_{i \in I_{1}} \ln P_{1 i}+\sum_{i \in I_{2}} \ln P_{2 i}
$$

\subsection{The average effect of part-time work on graduation probability}

The estimates for the bivariate probit model enable us to quantify the average effect of working part-time on success at the exam, while those of the model with a variable working time allow us to make this effect varying with the number of hours worked per week. For students with characteristics $X$ who hold a part-time job, the average effect of working part-time while studying on graduation is equal to, denoting by $Y_{2}^{k}$ the potential success

\footnotetext{
${ }^{18}$ An alternative specification, in particular more demanding in terms of identification conditions, would have consisted in adding an equation accounting for part-time work (extensive margin), with the third equation accounting for success at the exam and the second one for the number of hours worked (intensive margin). This specification would have also required larger samples.

${ }^{19}$ The individual subscript $i$ is omitted hereafter in order to alleviate the notational burden.
} 
at the exam when $Y_{1}=k$ :

$$
\begin{aligned}
\Delta_{T T}^{1}(X) & =E\left(Y_{2}^{1} \mid Y_{1}=1, X\right)-E\left(Y_{2}^{0} \mid Y_{1}=1, X\right) \\
& =\frac{\operatorname{Pr}\left(Y_{2}^{1}=1, Y_{1}=1 \mid X\right)}{\operatorname{Pr}\left(Y_{1}=1 \mid X\right)}-\frac{\operatorname{Pr}\left(Y_{2}^{0}=1, Y_{1}=1 \mid X\right)}{\operatorname{Pr}\left(Y_{1}=1 \mid X\right)}
\end{aligned}
$$

This effect corresponds to the treatment effect on the treated, the treatment being here the situation of working while studying. In the model with a varying working time, the effect on graduation of working less than 16 hours per week, conditional on observable characteristics $X$ and on working less than 16 hours per week, is:

$$
\begin{aligned}
\Delta_{T T}^{2}(X) & =E\left(Y_{2}^{1} \mid Y_{1}=1, X\right)-E\left(Y_{2}^{0} \mid Y_{1}=1, X\right) \\
& =\frac{\operatorname{Pr}\left(Y_{2}^{1}=1, Y_{1}=1 \mid X\right)}{\operatorname{Pr}\left(Y_{1}=1 \mid X\right)}-\frac{\operatorname{Pr}\left(Y_{2}^{0}=1, Y_{1}=1 \mid X\right)}{\operatorname{Pr}\left(Y_{1}=1 \mid X\right)}
\end{aligned}
$$

Finally, the average effect on success at the exam of working 16 hours or more per week is:

$$
\begin{aligned}
\Delta_{T T}^{3}(X) & =E\left(Y_{2}^{2} \mid Y_{1}=2, X\right)-E\left(Y_{2}^{0} \mid Y_{1}=2, X\right) \\
& =\frac{\operatorname{Pr}\left(Y_{2}^{2}=1, Y_{1}=2 \mid X\right)}{\operatorname{Pr}\left(Y_{1}=2 \mid X\right)}-\frac{\operatorname{Pr}\left(Y_{2}^{0}=1, Y_{1}=2 \mid X\right)}{\operatorname{Pr}\left(Y_{1}=2 \mid X\right)}
\end{aligned}
$$

In order to estimate these average effects for students who work part-time, unconditional on their characteristics $X$, we compute the empirical means of the conditional effects, denoted $\widehat{\Delta}_{T T}^{j}\left(X_{i}\right)$ for $j=1,2,3$ and $i=1, \ldots, n$. We further detail our analysis by estimating the average effect of working on success at the exam across various subgroups of students, according to a certain major or level of studies. ${ }^{20}$

\footnotetext{
${ }^{20}$ We also estimate the effect of part-time working on the graduation probability for students who do not work part-time, that is the treatment effect on the untreated. These effects are simply obtained from the treatment effect on the treated by replacing in the conditioning $\left\{Y_{1}=k\right\}$, with $k \in\{1,2\}$, by $\left\{Y_{1}=0\right\}$.
} 


\subsection{Results}

Table 2: The effect of part-time work on the graduation probability (single-equation probit model)

\begin{tabular}{lcc} 
Covariates & Estimates & St.errors \\
\hline Intercept & $0.718^{* * *}$ & 0.090 \\
\hline Part-time work & $-0.353^{* * *}$ & 0.110 \\
\hline Educational level & \\
Associate degree & $-0.760^{* * *}$ & 0.213 \\
Bachelor degree & Ref. & Ref. \\
Master degree & $-0.183^{* *}$ & 0.071 \\
\hline Major & & \\
Sciences & -0.063 & 0.087 \\
Law, humanities and social sciences & $R e f$. & $R e f$. \\
Management and trade & $-0.355^{* * *}$ & 0.085 \\
Other majors & -0.177 & 0.159 \\
\hline Age above the usual age in the grade & & \\
Usual age & Ref. & Ref. \\
One year above & $-0.219^{* * *}$ & 0.085 \\
Two years above or more & $-0.380^{* * *}$ & 0.080 \\
\hline Male & 0.035 & 0.070 \\
\hline Married & -0.219 & 0.220 \\
\hline
\end{tabular}

Source : French Labor Force Surveys, from 1992 to 2002 (INSEE, Paris). Sample size: $N=1,603$. Statistical significance levels: ${ }^{* *}(1 \%),{ }^{* *}(5 \%)$ and ${ }^{*}(10 \%)$. Year-specific dummies are also included in the estimation. 
Table 3: The effect of hours worked on the graduation probability (singleequation probit model)

\begin{tabular}{|c|c|c|}
\hline Covariates & Estimates & St.errors \\
\hline Intercept & $0.714^{* * *}$ & 0.090 \\
\hline \multicolumn{3}{|l|}{ Part-time work } \\
\hline Non-working & Ref. & Ref. \\
\hline Less than 16 hours per week & -0.158 & 0.146 \\
\hline 16 hours or more per week & $-0.538^{* * *}$ & 0.143 \\
\hline \multicolumn{3}{|l|}{ Educational level } \\
\hline Associate degree & $-0.765^{* * *}$ & 0.214 \\
\hline Bachelor degree & Ref. & Ref. \\
\hline Master degree & $-0.181^{* *}$ & 0.071 \\
\hline \multicolumn{3}{|l|}{ Major } \\
\hline Sciences & -0.067 & 0.087 \\
\hline Law, humanities and social sciences & Ref. & Ref. \\
\hline Management and trade & $-0.358^{* * *}$ & 0.086 \\
\hline Other majors & -0.121 & 0.162 \\
\hline \multicolumn{3}{|l|}{ Age above the usual age in the grade } \\
\hline Usual age & Ref. & Ref. \\
\hline One year above & $-0.217^{* *}$ & 0.085 \\
\hline Two years above or more & $-0.372^{* * *}$ & 0.080 \\
\hline Male & 0.034 & 0.07 \\
\hline Married & -0.216 & 0.22 \\
\hline
\end{tabular}

Source : French Labor Force Surveys, from 1992 to 2002 (INSEE, Paris). Sample size: $N=1,603$. Statistical significance levels: ${ }^{* *}(1 \%),{ }^{* *}(5 \%)$ and ${ }^{*}(10 \%)$. Year-specific dummies are also included in the estimation.

\subsubsection{Parameter estimates}

We first report the parameter estimates of the single-equation probit model (corresponding to a correlation coefficient $\sigma_{12}$ equal to zero) explaining the equation of success at the exam. This univariate model does not address the issue of the endogeneity of part-time work. Table 2 and Table 3 present the effect of part-time working and the effects of working more or less than 16 hours per week, respectively. On average, working part-time 
significantly decreases the probability of success at the exam (Table 2). Accounting for the number of hours worked actually suggests that this detrimental effect is only significant for intensive part-time employment, with 16 hours or more worked per week (Table 3). Nevertheless, as already mentioned, not taking into account the potential endogeneity of part-time work may bias these initial estimates. Hereafter, we will therefore focus on the simultaneous estimate of employment and success equations.

The estimates of the parameters of this simultaneous two-equations model are reported in Tables 4 (employment equation) and 5 (graduation equation). The parameters of the two equations of the model with a varying working time are reported in Tables 6 (employment equation) and 7 (graduation equation).

Once allowing for a non-zero correlation between the residuals of the employment and graduation equations, it appears that part-time working has a large negative and statistically significant (at the 1\% level) effect on the probability of passing the final exam (Table 5). This effect is in fact much stronger for students who work 16 hours or more per week than for those who work less than 16 hours per week (Table 7). The correlation coefficient between the residuals of the two equations is positive, statistically significant at the $1 \%$ level and quite large in the two models.

These results imply that working while studying is indeed endogenous. Thus, simple probit estimates reported in Tables 2 and 3 are biased. Furthermore, our results suggest that some positive selection effect is associated with part-time labor supply. This may be due to the fact that, on average, students working part-time are actually more motivated than the others, both from an academic and a professional point of view. Noteworthy, in our case, these single-equation specifications severely underestimate the detrimental effect of part-time work on the graduation probability. Relying on U.S. data, Tyler (2003), at the high-school level, and Stinebrickner \& Stinebrickner (2003) and Kalenkoski \& Pabilonia (2010), at the college level, also report positive selection effects.

Besides, our results suggest that the probability of working while studying is significantly lower for students whose father has a higher socio-economic status. ${ }^{21}$ As expected, this probability is also lower (at the $5 \%$ level) when the local unemployment rate of low-skilled youth is higher. In this case, however, students with a higher socio-economic background have a very significantly higher probability of finding a job. Moreover, the probability

\footnotetext{
${ }^{21}$ We also estimated an alternative specification of the employment equation, including a more detailed father's socio-economic status variable making a distinction between intermediate occupations, blue-collar and white-collar workers. The only significant coefficient was that of the higher socio-economic status defined above, thus suggesting that restricting to a binary socio-economic status variable is indeed relevant in our context.
} 
of working part-time is higher for students who are preparing a master degree, for those who have accumulated more than two years of school delay, and for those who live in households made up of one or two persons (see Table 4). It is also higher for students who are in majors other than Science, Social Sciences, Law and Arts, and Management, ${ }^{22}$ as well as, to a lesser extent, for those who are married. The overall findings are similar when accounting for the number of hours worked (see Table 6).

Graduation rates are significantly lower in the second year of an associate degree, as well as in Management and Trade, and for students who have accumulated some delay in education (cf. Tables 5 and 7). A noteworthy point is that the negative effect of studying in the second year of an associate degree, in comparison with a bachelor degree, is quantitatively fairly strong. This finding is consistent with the particularly high dropout rate prevailing in France in the first years of university studies.

\subsubsection{Robustness checks}

In order to assess the validity as an instrument of the local unemployment rate for the lowskilled workers under 29 , we have also run additional estimations accounting for schooling motivation. More precisely, we include in the set of regressors a variable which corresponds to the average, in each département, of the level of post-secondary education (in terms of years after high-school, ranging between 1 and 5) that the students want to reach when entering post-secondary education. This variable, that we refer to in the following as the average local educational aspiration, was computed from the Panel 1989 dataset (DEPP, French Ministry of Education). ${ }^{23}$ The parameter estimates are reported in Tables 15 and 16 in the Appendix. Overall, our main results are robust to this alternative specification. In particular, in the employment equation, the parameters relative to the local unemployment rate and its interaction with the father's socio-economic status are very stable. Similarly, the parameter estimates for the graduation equation, including the one associated with the part-time work effect, are robust to this alternative specification. Note also that the parameters relative to the aspiration variable are significant, respectively at the $10 \%$ and at the $1 \%$ level for the employment and the graduation equation, thus suggesting that motivation for schooling indeed matters. Interestingly enough, the estimate associated with the aspiration variable is actually positive for the employment equation, a result in

\footnotetext{
${ }^{22}$ These majors, in which courses are more oriented towards the labor market, concern $5.93 \%$ of our sample and consist in multi-technology majors (namely Civil Engineering, Mechanics and Electricity). Beffy et al. (2010) examine the determinants of the major choice in the French post-secondary system.

${ }^{23}$ This longitudinal dataset surveys individuals entering the $6^{\text {th }}$ grade in 1989, and who are enrolled in a French junior high-school at that date.
} 
line with the positive selection effect which was previously found.

Similarly, one could also argue that the father's socio-economic status has also a direct effect on academic achievement, and this would be an argument against excluding it from the graduation equation. Nonetheless, the data seem to reject this hypothesis: when we estimate our models without excluding the father's socio-economic status from the graduation equation, the assumption that there is no effect due to the father's socioeconomic background on passing the final exam cannot be rejected at the $10 \%$ level. ${ }^{24}$

\footnotetext{
${ }^{24}$ Detailed results for this specification are available upon request.
} 
Table 4: The bivariate probit model: determinants of part-time work

\begin{tabular}{lcc} 
Covariates & Estimates & St.errors \\
\hline Intercept & $-0.787^{* * *}$ & 0.283 \\
\hline Father's socio-economic status & $-1.953^{* * *}$ & 0.590 \\
Higher & $R e f$. & $R e f$. \\
Lower or intermediate & $-0.025^{* *}$ & 0.011 \\
\hline Local unskilled unemployment rate for the individuals aged 15 to 29 & $0.071^{* * *}$ & 0.027 \\
Higher socio-economic status $\times$ unemployment rate & & \\
\hline Educational level & 0.051 & 0.335 \\
Associate degree & $R e f$. & $R e f$. \\
Bachelor degree & $0.34^{* * *}$ & 0.097 \\
Master degree & & \\
\hline Major & -0.161 & 0.136 \\
Sciences & $R e f$. & $R e f$. \\
Law, humanities and social sciences & 0.145 & 0.118 \\
Management and trade & $1.664^{* * *}$ & 0.162 \\
Other majors & & \\
\hline Age above the usual age in the grade & $R e f$. & $R e f$. \\
Usual age & 0.110 & 0.127 \\
One year above & $0.551^{* * *}$ & 0.108 \\
Two years above or more & 0.073 & 0.098 \\
\hline Male & -0.048 & 0.153 \\
\hline Children under 18 in the household & $0.446^{*}$ & 0.256 \\
\hline Married & $-0.437^{* * *}$ & 0.103 \\
\hline Three and more persons in the household & 0.124 & 0.124 \\
\hline Paris region & & \\
\hline \hline & & \\
\hline
\end{tabular}

Source : French Labor Force Surveys, from 1992 to 2002 (INSEE, Paris). Sample size: $N=1,603$. Statistical significance levels: ${ }^{* *}(1 \%),{ }^{* *}(5 \%)$ and ${ }^{*}(10 \%)$. Year-specific dummies are also included in the estimation. 
Table 5: The bivariate probit model: the effect of part-time work on the graduation probability

\begin{tabular}{lcc} 
Covariates & Estimates & St.errors \\
\hline Intercept & $0.746^{* * *}$ & 0.088 \\
\hline Part-time work & $-1.384^{* * *}$ & 0.274 \\
\hline Educational level & \\
Associate degree & $-0.738^{* * *}$ & 0.211 \\
Bachelor degree & Ref. & Ref. \\
Master degree & -0.116 & 0.072 \\
\hline Major & -0.078 & 0.085 \\
Sciences & $R e f$. & $R e f$. \\
Law, humanities and social sciences & $-0.312^{* * *}$ & 0.085 \\
Management and trade & $0.432^{*}$ & 0.221 \\
\hline Other majors & & \\
\hline Age above the usual age in the grade & Ref. & Ref. \\
Usual age & $-0.193^{* *}$ & 0.084 \\
One year above & $-0.243^{* * *}$ & 0.087 \\
Two years above or more & 0.035 & 0.068 \\
\hline Male & -0.091 & 0.216 \\
\hline Married & $0.582^{* * *}$ & 0.148 \\
\hline$\sigma_{12}$ & \\
\hline \hline
\end{tabular}

Source : French Labor Force Surveys, from 1992 to 2002 (INSEE, Paris). Sample size: $N=1,603$. Statistical significance levels: ${ }^{* *}(1 \%),{ }^{* *}(5 \%)$ and ${ }^{*}(10 \%)$. Year-specific dummies are also included in the estimation. 
Table 6: The two -equations model with varying working-time: determinants of the number of hours worked

Covariates

Estimates St. errors

\begin{tabular}{lcc}
\hline$s_{2}$ & $0.786^{* * *}$ & 0.273 \\
$s_{3}$ & $1.216^{* * *}$ & 0.275 \\
\hline Father's social status & & \\
Higher & $-1.849^{* * *}$ & 0.570 \\
Lower or intermediate & Ref. & Ref. \\
\hline Local unskilled unemployment rate for the individuals aged 15 to 29 & $-0.026^{* *}$ & 0.011 \\
Higher socio-economic status $\times$ unemployment rate & $0.067^{* * *}$ & 0.026 \\
\hline Associate degree & 0.032 & 0.331 \\
Bachelor degree & $R e f$. & $R e f$. \\
Master degree & $0.343^{* * *}$ & 0.093 \\
\hline Sciences & -0.191 & 0.135 \\
Law, humanities and social sciences & $R e f$. & $R e f$. \\
Management and trade & 0.127 & 0.116 \\
Other majors & $1.574^{* * *}$ & 0.147 \\
\hline Age above the usual age in the grade & & \\
Usual age & $R e f$. & $R e f$. \\
One year above & 0.120 & 0.124 \\
Two years above or more & $0.572^{* * *}$ & 0.105 \\
\hline Male & 0.081 & 0.095 \\
\hline Children under 18 in the household & -0.009 & 0.149 \\
\hline Married & 0.361 & 0.238 \\
\hline Three and more persons in the household & $-0.462^{* * *}$ & 0.100 \\
\hline Paris region & 0.101 & 0.120 \\
\hline \hline & & \\
\hline
\end{tabular}

Source : French Labor Force Surveys, from 1992 to 2002 (INSEE, Paris). Sample size: $N=1,603$. Statistical significance levels: ${ }^{* *}(1 \%),{ }^{* *}(5 \%)$ and ${ }^{*}(10 \%)$. Year-specific dummies are also included in the estimation. 
Table 7: The two -equations model with varying working-time: the effect of hours worked on the graduation probability

\begin{tabular}{|c|c|c|}
\hline Covariates & Estimates & St.errors \\
\hline Intercept & $0.739^{* * *}$ & 0.090 \\
\hline \multicolumn{3}{|l|}{ Part-time work } \\
\hline Non-working & Ref. & Ref. \\
\hline Less than 16 hours per week & $-0.833^{* * *}$ & 0.254 \\
\hline 16 hours or more per week & $-1.478^{* * *}$ & 0.318 \\
\hline \multicolumn{3}{|l|}{ Educational level } \\
\hline Associate degree & $-0.758^{* * *}$ & 0.212 \\
\hline Bachelor degree & Ref. & Ref. \\
\hline Master degree & $-0.128^{*}$ & 0.072 \\
\hline \multicolumn{3}{|l|}{ Major } \\
\hline Sciences & -0.083 & 0.086 \\
\hline Law, humanities and social sciences & Ref. & Ref. \\
\hline Management and trade & $-0.328^{* * *}$ & 0.085 \\
\hline Other majors & $0.396^{*}$ & 0.230 \\
\hline \multicolumn{3}{|l|}{ Age above the usual age in the grade } \\
\hline Usual age & Ref. & Ref. \\
\hline One year above & $-0.196^{* *}$ & 0.084 \\
\hline Two years above or more & $-0.259^{* * *}$ & 0.088 \\
\hline Male & 0.033 & 0.068 \\
\hline Married & -0.115 & 0.218 \\
\hline$\sigma_{12}$ & $0.454^{* * *}$ & 0.150 \\
\hline
\end{tabular}

Source : French Labor Force Surveys, from 1992 to 2002 (INSEE, Paris). Sample size: $N=1,603$. Statistical significance levels: ${ }^{* *}(1 \%),{ }^{* *}(5 \%)$ and ${ }^{*}(10 \%)$. Year-specific dummies are also included in the estimation.

\subsubsection{The effect of part-time work on graduation probability}

The parameter estimates of the bivariate probit model enable us to compute, for each of the 202 students who work, their probability of graduating if they did not work. The actual graduation probability in the case of working part-time and the counterfactual probability 
that would prevail if they did not work are then compared. The differences between these two probabilities are reported in Table 8, first for the whole sample, then for each major and for each level of education. ${ }^{25}$

Using the parameter estimates of the the first bivariate probit model, working part-time is found to have a significant and very large detrimental effect on the probability of passing the exam, whatever the major and the level of studies are. ${ }^{26}$ If they did not work, working students would have a probability higher by slightly less than 43 points of passing their year-end exam (Table 8). Given the endogeneity of part-time work, the effect of working while studying is not necessarily the same when it is estimated for working and nonworking students. Thus, we also estimate the effect of working while studying for students who do not hold a job (Table 9). We find similar results: on average, holding a part-time job would lower their probability of passing the exam by about 47 points. Interestingly, these estimates are especially strong relative to prior empirical evidence on the effect of part-time work on academic achievement. This may stem from the fact that, as compared in particular with the U.S. post-secondary educational system, most of French university courses are more theoretical and less vocationally oriented, and are therefore less subject to complementarities between part-time work and academic achievement. Moreover, evening classes and continuous assessment all over the academic year, which are more suitable for part-time working students, are very unfrequent in French universities (see Aghion \& Cohen, 2004).

Using the parameter estimates of the second model with a varying working time, we also compute, for students working more or less than 16 hours per week, the counterfactual probabilities of success in the case where they would not work. Table 10 shows that the estimated effect of working is very sensitive to the number of hours worked, a result in line with the existing empirical evidence. On the one hand, working 16 hours or more per week has a very significantly negative effect (on average close to 48 points) on the probability of graduating. On the other hand, the effect of working less than 16 hours per week is much smaller, and only significant at the $10 \%$ level for those holding a part-time job (about 28 points). This suggests that a substantial volume of hours worked per week steeply reduces the time devoted to studies as well as, potentially, students' attendance, and as a result has a negative effect on the graduation probability. By contrast, holding a job that requires a low number of hours worked (in this case less than 16 hours per week) seems to limit these

\footnotetext{
${ }^{25}$ Note that the average effect of working while studying depends on individual characteristics via the non-linearity of the models. Thus, the heterogeneity of average effects according to majors reflects both a composition effect and a major-specific effect.

${ }^{26}$ The standard deviations are computed by bootstrap, with 500 replications.
} 
negative substitution effects. Table 11 reports the results for the subsample of students who do not work. The results are once again similar.

Table 8: Average effect of part-time work on the graduation probability (subsample of working students), bivariate probit model

\begin{tabular}{llc}
$\begin{array}{l}\text { Effect on the graduation probability } \\
\text { (percentage points) }\end{array}$ & Estimate & St. error \\
\hline Working students & $-42.6^{* * *}$ & 14.9 \\
\hline Major & $-35.8^{* *}$ & 17.0 \\
Sciences & $-38.6^{* *}$ & 16.4 \\
Law, humanities and social sciences & $-46.3^{* * *}$ & 13.8 \\
Management and trade & $-46.7^{* * *}$ & 13.8 \\
Other majors & & \\
\hline Educational level & $-45.9^{* * *}$ & 12.9 \\
Associate degree & $-41.0^{* * *}$ & 15.0 \\
Bachelor degree & $-44.5^{* * *}$ & 14.9 \\
Master degree &
\end{tabular}

Source : French Labor Force Surveys, from 1992 to 2002 (INSEE, Paris). Sample size: $N=1,603$. Statistical significance levels: ${ }^{* *}(1 \%),{ }^{* *}(5 \%)$ and ${ }^{*}(10 \%)$. 
Table 9: Average effect of part-time work on the graduation probability (subsample of non-working students), bivariate probit model

\begin{tabular}{llc}
$\begin{array}{l}\text { Effect on the graduation probability } \\
\text { (percentage points) }\end{array}$ & Estimate & St. error \\
\hline Non-working students & $-47.1^{* * *}$ & 9.22 \\
\hline Major & & \\
Sciences & $-47.8^{* * *}$ & 9.71 \\
Law, humanities and social sciences & $-48.3^{* * *}$ & 9.72 \\
Management and trade & $-43.2^{* * *}$ & 7.84 \\
Other majors & $-46.0^{* * *}$ & 10.4 \\
\hline Educational level & & \\
Associate degree & $-34.0^{* * *}$ & 8.04 \\
Bachelor degree & $-48.1^{* * *}$ & 9.65 \\
Master degree & $-45.8^{* * *}$ & 8.76
\end{tabular}

Source: French Labor Force Surveys, from 1992 to 2002 (INSEE, Paris). Sample size: $N=1,603$. Statistical significance levels: ${ }^{* *}(1 \%),{ }^{* *}(5 \%)$ and ${ }^{*}(10 \%)$. 
Table 10: Average effect of hours worked on the graduation probability (subsample of working students), model with a varying working time

\begin{tabular}{llc}
$\begin{array}{l}\text { Effect on the graduation probability } \\
\text { (percentage points) }\end{array}$ & Estimate & St. error \\
\hline Less than $\mathbf{1 6}$ hours per week & & \\
\hline Average effect & $-27.6^{*}$ & 16.3 \\
\hline Major & & \\
Sciences & -26.3 & 17.0 \\
Law, humanities and social sciences & -26.0 & 16.6 \\
Management and trade & $-29.1^{*}$ & 15.9 \\
Other majors & $-30.0^{*}$ & 16.6 \\
\hline Educational level & & \\
Associate degree & $-27.3^{*}$ & 15.0 \\
Bachelor degree & -26.7 & 16.4 \\
Master degree & $-28.8^{*}$ & 16.4 \\
\hline \hline
\end{tabular}

16 hours or more per week

\begin{tabular}{lll}
\hline Average effect & $-47.5^{* * *}$ & 9.86 \\
\hline Major & & \\
Sciences & $-38.7^{* * *}$ & 13.9 \\
Law, humanities and social sciences & $-44.6^{* * *}$ & 11.7 \\
Management and trade & $-49.1^{* * *}$ & 8.99 \\
Other majors & $-50.1^{* * *}$ & 9.03 \\
\hline Educational level & & \\
Associate degree & $-45.1^{* * *}$ & 12.1 \\
Bachelor degree & $-46.9^{* * *}$ & 9.98 \\
Master degree & $-48.3^{* * *}$ & 9.97 \\
\hline
\end{tabular}

Source: French Labor Force Surveys, from 1992 to 2002 (INSEE, Paris). Sample size: $N=1,603$. Statistical significance levels: ${ }^{* *}(1 \%),{ }^{* *}(5 \%)$ and ${ }^{*}(10 \%)$. 
Table 11: Average effect of hours worked on the graduation probability (subsample of non-working students), model with a varying working time

\begin{tabular}{llc}
$\begin{array}{l}\text { Effect on the graduation probability } \\
\text { (percentage points) }\end{array}$ & Estimate & St. error \\
\hline Less than $\mathbf{1 6}$ hours per week & & \\
\hline Average effect & $-28.3^{* *}$ & 14.4 \\
\hline Major & & \\
Sciences & $-28.3^{*}$ & 14.6 \\
Law, humanities and social sciences & $-28.7^{*}$ & 14.8 \\
Management and trade & $-27.1^{* *}$ & 13.3 \\
Other majors & $-27.8^{*}$ & 14.5 \\
\hline Educational level & & \\
Associate degree & $-22.4^{* *}$ & 11.2 \\
Bachelor degree & $-28.6^{*}$ & 14.7 \\
Master degree & $-28.0^{* *}$ & 14.1 \\
\hline \hline
\end{tabular}

\begin{tabular}{lll}
\hline \hline $\mathbf{1 6}$ hours or more per week & & \\
\hline Average effect & $-48.2^{* * *}$ & 6.35 \\
\hline Major & & \\
Sciences & $-48.6^{* * *}$ & 6.59 \\
Law, humanities and social sciences & $-49.6^{* * *}$ & 6.32 \\
Management and trade & $-44.1^{* * *}$ & 7.05 \\
Other majors & $-48.3^{* * *}$ & 7.18 \\
\hline Educational level & & \\
Associate degree & $-34.6^{* * *}$ & 8.63 \\
Bachelor degree & $-49.2^{* * *}$ & 6.30 \\
Master degree & $-47.0^{* * *}$ & 6.79 \\
\hline
\end{tabular}

Source : French Labor Force Surveys, from 1992 to 2002 (INSEE, Paris). Sample size: $N=1,603$. Statistical significance levels: ${ }^{* *}(1 \%),{ }^{* *}(5 \%)$ and ${ }^{*}(10 \%)$. 


\section{The impact of part-time work on the decision to stay on in education}

The lack of financial resources can induce students to work part-time in order to finance their studies. As already seen before, working part-time while studying is found to have a detrimental impact on the graduation probability, especially when occupied jobs are intensive. Nonetheless, does this situation lower a student's probability of staying on in education? One could imagine that a student who works today is building up savings that will enable her to more easily finance her studies in the following year and potentially to cope with credit constraints. From this point of view, holding a part-time job may actually have a positive effect on the continuation of studies.

In order to quantify the effect of part-time work on the decision to stay on in education, we now consider a model accounting for both success at the year-end exam and for the decision to continue the following year.

\subsection{Modeling the decision to stay on in education}

The first equation accounts for part-time work $\left(Y_{1}=1\right.$ when the student holds a part-time job, 0 otherwise). The second equation jointly accounts for success at the year-end exam and for the decision to stay on in education or to drop out: ${ }^{27}$ the related variable $Y_{2}$ takes four values, depending on whether the student fails the exam and drops out $\left(Y_{2}=0\right)$, passes the exam and drops out $\left(Y_{2}=1\right)$, fails and accepts to repeat the year $\left(Y_{2}=2\right)$, or passes the exam and stay on in education $\left(Y_{2}=3\right) .{ }^{28}$ This specification leads to a model with two equations, which are simultaneously estimated. The first one is a simple probit equation, the second one an ordered probit equation. ${ }^{29}$

Similarly to the previous section, the student decides to work part-time while studying (in which case $Y_{1}=1$ ) if the latent variable $Y_{1}^{*}$ defined by the equation $Y_{1}^{*}=X_{1} \beta_{1}+\varepsilon_{1}$

\footnotetext{
${ }^{27}$ When a student fails the exam, the decision to stay on in education implies grade repetition.

${ }^{28}$ We have tested the sensitivity of our estimates with respect to the order chosen for these four values, by estimating a model such that the alternative associated with dropping out after passing the exam dominates the alternative associated with repeating the year. Our main results are robust to this alternative specification.

${ }^{29}$ Estimating a more complex model, taking in particular into account the number of hours worked, but also, with a supplementary equation, the decision to continue, would require to find instrumental variables that would affect the probability of passing the exam but not the decision to stay on in education. Unfortunately, there are no natural candidates for such instruments in our data.
} 
is positive. Graduation and continuation are jointly modeled by a variable $Y_{2}$ whose four values have been described above. Specifically, we rely on an ordered probit model of the form:

$$
\forall k \in\{0,1,2,3\}, \quad Y_{2}=k \Leftrightarrow \alpha_{k}<Y_{2}^{*}=Y_{1} \beta_{20}+X_{2} \beta_{21}+\varepsilon_{2} \leq \alpha_{k+1}
$$

where $Y_{2}^{*}$ refers to the individual propensity to graduate and stay on in education. This propensity is supposed to depend first of all on holding a part-time job, which is a potentially endogenous variable, but also on a vector $X_{2}$ of individual characteristics such as major, gender, etc. The vector of parameters $\beta_{2}=\left(\beta_{20}, \beta_{21}\right)^{\prime}$ associated with the explanatory variables $Y_{1}$ and $X_{2}$, must be jointly estimated with the thresholds $\alpha_{1}, \alpha_{2}$ and $\alpha_{3} .{ }^{30}$ Once again, $\varepsilon_{2}$ is supposed to follow a normal standard distribution $\mathcal{N}(0,1)$.

We denote $I_{1}$ the subsample of students who do not work part-time $\left(Y_{1}=0\right)$ and $I_{2}$ the subsample of working students $\left(Y_{1}=1\right)$. The contribution to the likelihood of the individual $i$ in the sample of size $n$, denoted $P_{k i}$ ( $k$ indicating the student's status, that is working part-time or not), is as follows:

$$
\begin{array}{r}
i \in I_{1} \Rightarrow \quad P_{1 i}=\Phi_{2}\left(-X_{1 i} \beta_{1}, \alpha_{Y_{2 i}+1}-X_{2 i} \beta_{21}, \sigma_{12}\right) \\
-\Phi_{2}\left(-X_{1 i} \beta_{1}, \alpha_{Y_{2 i}}-X_{2 i} \beta_{21}, \sigma_{12}\right) \\
i \in I_{2} \Rightarrow \quad P_{2 i}=\Phi_{2}\left(X_{1 i} \beta_{1}, \alpha_{Y_{2 i}+1}-\beta_{20}-X_{2 i} \beta_{21},-\sigma_{12}\right) \\
-\Phi_{2}\left(X_{1 i} \beta_{1}, \alpha_{Y_{2 i}}-\beta_{20}-X_{2 i} \beta_{21},-\sigma_{12}\right)
\end{array}
$$

The log-likelihood for the whole sample is then written:

$$
\ln L=\sum_{i \in I_{1}} \ln P_{1 i}+\sum_{i \in I_{2}} \ln P_{2 i}
$$

\subsection{The average effect of part-time work on the decision to stay on in educa- tion}

The parameter estimates enable us to compute the average effect of working part-time on the decision to stay on in education. Denoting $Y_{2}^{2}(k)$ the potential decision to stay on in education when $Y_{1}=k$, the average effect of working part-time on the decision to stay on

\footnotetext{
${ }^{30}$ We set $\alpha_{0}=-\infty$ and $\alpha_{4}=+\infty$.
} 
in education for students who hold a part-time job is equal to:

$$
\begin{aligned}
\Delta_{T T 2}^{1}(X) & =\quad E\left(Y_{2}^{2}(1) \mid Y_{1}=1, X\right)-E\left(Y_{2}^{2}(0) \mid Y_{1}=1, X\right) \\
& =\left(\operatorname{Pr}\left(Y_{2}(1)=3 \mid Y_{1}=1, X\right)-\operatorname{Pr}\left(Y_{2}(0)=3 \mid Y_{1}=1, X\right)\right) \\
& +\left(\operatorname{Pr}\left(Y_{2}(1)=1 \mid Y_{1}=1, X\right)-\operatorname{Pr}\left(Y_{2}(0)=1 \mid Y_{1}=1, X\right)\right)
\end{aligned}
$$

with :

$$
\operatorname{Pr}\left(Y_{2}(k)=y_{2} \mid Y_{1}=1, X\right)=\frac{\operatorname{Pr}\left(Y_{2}(k)=y_{2}, Y_{1}=1 \mid X\right)}{\operatorname{Pr}\left(Y_{1}=1 \mid X\right)}
$$

\section{$5.3 \quad$ Results}

\subsubsection{Parameter estimates}

The parameter estimates of the previous model are reported in Table 12 (success at the exam and decision to stay on in education). ${ }^{31}$ First of all, note that the exclusion restrictions on which we rely on are not exactly the same as those introduced in the previous section. Indeed, the student's socio-economic background can directly affect the decision to stay on in education while still affecting the decision to work part-time, likely because it is a proxy for parental income and therefore for their ability to finance their children's university studies. For this reason, the father's socio-economic status should not be excluded from the equation accounting for graduation and continuation. Therefore, we only use variations in the local unemployment rate of low-skilled youth, as well as in its interaction with the dummy for the student's socio-economic background, to identify the effect of part-time work on the success at the year-end exam and on the decision to stay on in education. Since the decision to drop out from university may be related to labor market conditions affecting the opportunity cost of education, we also include the local unemployment rate in the set of regressors affecting the success at the year-end exam and the decision to stay on in education. ${ }^{32}$

Unlike previous estimates that did not take the decision to stay on in education into account, the correlation between the residuals of the two equations is no longer significantly different from zero: the selection bias related to the decision work part-time while studying

\footnotetext{
${ }^{31}$ The results for the employment equation are not reported here since the estimates are similar to those of the employment equation presented in the previous section.

${ }^{32}$ This unemployment rate is also computed from the French Censuses of 1990 and 1999. It is defined, at the level of each département, as the overall unemployment rate of the whole labor force.
} 
can therefore be ignored. Furthermore, the coefficient associated with part-time working while studying (-0.562) is not significant in the equation of success at the year-end exam and the decision to stay on in education.

Table 12: Effect of part-time work on graduation and enrollment the following year

\begin{tabular}{|c|c|c|}
\hline Covariates & Estimates & St.errors \\
\hline$s_{2}$ & $-2.28^{* * *}$ & 0.162 \\
\hline$s_{3}$ & $-1.89^{* * *}$ & 0.160 \\
\hline$s_{4}$ & $-0.784^{* * *}$ & 0.164 \\
\hline Part-time work & -0.562 & 0.398 \\
\hline Local unemployment rate & 0.001 & 0.011 \\
\hline Father with a high socio-economic status & 0.086 & 0.084 \\
\hline \multicolumn{3}{|l|}{ Educational level } \\
\hline Associate degree & $-0.538^{* * *}$ & 0.191 \\
\hline Bachelor degree & Ref. & Ref. \\
\hline Master degree & $-0.360^{* * *}$ & 0.07 \\
\hline \multicolumn{3}{|l|}{ Major } \\
\hline Sciences & 0.025 & 0.08 \\
\hline Law, humanities and social sciences & Ref. & Ref. \\
\hline Management and trade & $-0.21^{* * *}$ & 0.079 \\
\hline Other majors & 0.135 & 0.257 \\
\hline \multicolumn{3}{|l|}{ Age above the usual age in the grade } \\
\hline Usual age & Ref. & Ref. \\
\hline One year above & $-0.287^{* * *}$ & 0.078 \\
\hline Two years above or more & $-0.625^{* * *}$ & 0.087 \\
\hline Children under 18 in the household & -0.018 & 0.089 \\
\hline Three persons and more in the household & 0.063 & 0.074 \\
\hline Male & $-0.134^{* *}$ & 0.064 \\
\hline Married & $-0.444^{* *}$ & 0.196 \\
\hline Paris region & $-0.154^{* *}$ & 0.078 \\
\hline$\sigma_{12}$ & 0.180 & 0.207 \\
\hline
\end{tabular}

Source : French Labor Force Surveys, from 1992 to 2002 (INSEE, Paris). Sample size: $N=1,603$. Statistical significance levels: ${ }^{* *}(1 \%),{ }^{* *}(5 \%)$ and ${ }^{*}(10 \%)$. Year-specific dummies are also included in the estimation. 


\subsubsection{The effect of part-time work on the decision to stay on in education}

The parameter estimates of the preceding model enable us to compute, for each of the 202 students who work, the probability of staying on in education if they did not work. The actual probability of continuing the following year in the case of working while studying and the counterfactual probability that would prevail in the absence of part-time work are therefore compared. The differences between these two probabilities are reported in Table 13, by distinguishing between majors and educational levels.

Consistently with the preceding parameter estimates, holding a part-time job has a nonsignificant effect on the probability to continue studies, whatever the major and the level of studies (Table 13). Similarly, if students who do not work part-time were to work, their probability of staying on in education would not be significantly modified (see Table 14). These results therefore suggest that, while holding a part-time job has a strong detrimental impact on the graduation probability, it does not have any significant effect on continuation. ${ }^{33}$

\footnotetext{
${ }^{33}$ Interestingly, such a pattern is consistent with the credit constraint explanation given above.
} 
Table 13: Effect of a part-time work on the probability to continue the following year (subsample of working students)

Effect on the enrollment probability Estimate St. error (percentage points)

\section{Success and continuation}

\begin{tabular}{lcc}
\hline Average effect & -18.1 & 15.5 \\
\hline Major & -18.8 & 16.3 \\
Sciences & -18.6 & 15.9 \\
Law, humanities and social sciences & -17.4 & 14.8 \\
Management and trade & -17.9 & 15.3 \\
Other majors & & \\
\hline Educational level & -15.0 & 13.5 \\
Associate degree & -18.6 & 15.9 \\
Bachelor degree & -17.7 & 15.1 \\
Master degree & & \\
\hline \hline Failure and repetition & 4.5 & 6.4 \\
\hline Average effect & & \\
\hline Major & 8.0 & 7.7 \\
Sciences & 6.1 & 6.9 \\
Law, humanities and social sciences & 2.7 & 6.3 \\
Management and trade & 2.8 & 6.5 \\
Other majors & & \\
\hline Educational level & -2.9 & 8.5 \\
Associate degree & 6.4 & 6.7 \\
Bachelor degree & & \\
Master degree & & \\
\hline
\end{tabular}

Source : French Labor Force Surveys, from 1992 to 2002 (INSEE, Paris). Sample size: $N=1,603$. Statistical significance levels: ${ }^{* *}(1 \%),{ }^{* *}(5 \%)$ and ${ }^{*}(10 \%)$. 
Table 14: Effect of a part-time work on the probability to continue the following year (subsample of non-working students)

Effect on the enrollment probability Estimate St. error (percentage points)

\begin{tabular}{lcc}
\hline Success and continuation & & \\
\hline Average effect & -19.5 & 14.5 \\
\hline Major & -19.9 & 14.9 \\
Sciences & -19.7 & 14.6 \\
Law, humanities and social sciences & -18.7 & 13.8 \\
Management and trade & -17.9 & 13.4 \\
Other majors & & \\
\hline Educational level & -16.8 & 12.7 \\
Associate degree & -20.1 & 15.0 \\
Bachelor degree & -18.5 & 13.6 \\
Master degree & & \\
\hline \hline Failure and repetition & 4.5 & 6.4 \\
\hline Average effect & & \\
\hline Major & 5.7 & 6.8 \\
Sciences & 4.9 & 6.4 \\
Law, humanities and social sciences & 2.2 & 6.4 \\
Management and trade & 1.9 & 6.1 \\
Other majors & & \\
\hline Educational level & 1.2 & 7.0 \\
Associate degree & & \\
Bachelor degree & & \\
Master degree & & \\
\hline & & \\
\hline & & \\
\hline
\end{tabular}

Source : French Labor Force Surveys, from 1992 to 2002 (INSEE, Paris). Sample size: $N=1,603$. Statistical significance levels: ${ }^{* *}(1 \%),{ }^{* *}(5 \%)$ and ${ }^{*}(10 \%)$. 


\section{Conclusion}

This paper contributes to the scarce literature dealing with the effect of part-time work on post-secondary educational attainment, by estimating the impact of working parttime both on college graduation and continuation, relying on data from a nationallyrepresentative survey. The findings reported in this article suggest that working while studying significantly reduces the probability of passing the university year-end exam. Our estimates show that this detrimental effect is very large, with the average probability of success of working students being about 43 points higher if they did not work. Consistently with the existing literature, we also find that the part-time work effect depends on the number of hours worked. Working 16 hours or more per week has a negative, and quantitatively very strong effect (on average of about 48 points) on the probability of graduating. Conversely, the effect of part-time work is much smaller when the student works less than 16 hours per week. From a policy point of view, taxation reforms giving students an incentive to increase the number of hours worked, which are currently discussed in France, might therefore have a perverse effect by indirectly leading to a rise in the rate of failure at university exams. The problem is all the more acute as our estimates suggest that the detrimental effect of part-time work on educational attainment is especially strong in the French university system, in which evening classes and continuous assessment of students are quite uncommon. Still, a complementary analysis shows that combining working and studying does not have any significant effect on the probability of continuing the following year, whatever the major and the level of studies. It is nevertheless important to stress that in this paper, we only consider the short-term effect of part-time work on academic attainment. Given that part-time work is likely to affect the whole process of human capital accumulation, an interesting avenue for further research, that would require to follow individuals for a longer period, would consist in investigating the medium-term effects of part-time work on academic attainment, in particular on the probability to stay on in education. 


\section{Appendix: additional estimates}

Table 15: A bivariate probit model accounting for educational aspiration: the determinants of part-time work

\begin{tabular}{lcc} 
Covariates & Estimates & St.errors \\
\hline Intercept & $-0.185^{* * *}$ & 0.635 \\
\hline Father's socio-economic status & $-1.934^{* * *}$ & 0.590 \\
Higher & Ref. & Ref. \\
Lower or intermediate & $-0.024^{* *}$ & 0.011 \\
\hline Local unskilled unemployment rate for the individuals aged 15 to 29 & $0.071^{* * *}$ & 0.027 \\
Higher socio-economic status $\times$ unemployment rate & & \\
\hline Educational level & 0.06 & 0.334 \\
Associate degree & $R e f$. & $R e f$. \\
Bachelor degree & $0.345^{* * *}$ & 0.097 \\
Master degree & & \\
\hline Major & -0.167 & 0.136 \\
Sciences & $R e f$. & $R e f$. \\
Law, humanities and social sciences & 0.140 & 0.118 \\
Management and trade & $1.664^{* * *}$ & 0.162 \\
\hline Other majors & & \\
\hline Age above the usual age in the grade & $R e f$. & $R e f$. \\
Usual age & 0.102 & 0.128 \\
One year above & $0.557^{* * *}$ & 0.108 \\
\hline Two years above or more & 0.083 & 0.099 \\
\hline Male & -0.054 & 0.153 \\
\hline Children under 18 in the household & $0.449^{*}$ & 0.257 \\
\hline Married & $-0.462^{* * *}$ & 0.104 \\
\hline Three persons and more in the household & $0.324^{* *}$ & 0.163 \\
\hline Paris region & $0.460^{*}$ & 0.245 \\
\hline Average local educational aspiration & &
\end{tabular}

Source : French Labor Force Surveys, from 1992 to 2002 (INSEE, Paris). Sample size: $N=1,603$. Statistical significance levels: ${ }^{* *}(1 \%),{ }^{* *}(5 \%)$ and ${ }^{*}(10 \%)$. Year-specific dummies are also included in the estimation. 
Table 16: A bivariate probit model accounting for educational aspiration: the effect of part-time work on the graduation probability

\begin{tabular}{lcc} 
Covariates & Estimates & St.errors \\
\hline Intercept & -0.008 & 0.284 \\
\hline Part-time work & $-1.377^{* * *}$ & 0.275 \\
\hline Educational level & \\
Associate degree & $-0.700^{* * *}$ & 0.212 \\
Bachelor degree & Ref. & Ref. \\
Master degree & -0.107 & 0.072 \\
\hline Major & -0.086 & \\
Sciences & $R e f$. & $R e f$. \\
Law, humanities and social sciences & $-0.317^{* * *}$ & 0.085 \\
Management and trade & $0.429^{*}$ & 0.222 \\
Other majors & $R e f$. & \\
\hline Age above the usual age in the grade & $R e f$. \\
Usual age & $-0.200^{* *}$ & 0.084 \\
One year above & $-0.237^{* * *}$ & 0.087 \\
Two years above or more & 0.035 & 0.069 \\
\hline Male & -0.090 & 0.216 \\
\hline Married & $0.349^{* * *}$ & 0.125 \\
\hline Average local educational aspiration & $0.577^{* * *}$ & 0.148 \\
\hline$\sigma_{12}$ & &
\end{tabular}

Source : Labor Force Surveys, from 1992 to 2002 (INSEE. Paris). Sample size: $N=1,603$. Statistical significance levels: ${ }^{* * *}(1 \%),{ }^{* *}(5 \%)$ and ${ }^{*}(10 \%)$. Year-specific dummies are also included in the estimation. 


\section{References}

Aghion, P. \& Cohen, E. (2004), Education et croissance, Conseil d'Analyse Economique, Rapport No. 46, La Documentation Française, Paris.

Beffy, M., Fougère, D. \& Maurel, A. (2010), 'Choosing the field of study in post-secondary education: Do expected earnings matter?', forthcoming in the Review of Economics and Statistics .

Buscha, F., Maurel, A., Page, L. \& Speckesser, S. (2008), The effect of high school employment on educational attainment: a conditional difference-in-differences approach. IZA Discussion Paper No 3696.

D'Amico, R. (1984), 'Does employment during high school impair academic progress?', Sociology of Education 57, 152-164.

Dustmann, C. \& van Soest, A. (2007), 'Part-time work, school success and school leaving', Empirical Economics 32, 277-299.

Eckstein, Z. \& Wolpin, K. (1999), 'Why youths drop out of high school: The impact of preferences, opportunities and abilities', Econometrica 67, 1295-1339.

Ehrenberg, R. \& Sherman, D. (1987), 'Employment while in college, academic achievement, and post-college outcomes: A summary of results', The Journal of Human Resources $\mathbf{2 2}, 1-23$.

Gade, E. \& Peterson, L. (1980), 'A comparison of working and nonworking high school students on school performance, socioeconomic status, and self-esteem', The Vocational Guidance Quarterly 29, 65-68.

Greenberger, E., Steinberg, L., Vaux, A. \& McAuliffe, S. (1980), 'Adolescents who work: Effects of part-time employment on family and peer relations', Journal of Youth and Adolescence 9, 189-202.

Heckman, J. (1978), 'Dummy endogenous variables in a simultaneous equation system', Econometrica 46, 931-959.

Hotchkiss, L. (1986), Work and Schools: Complements and Competitors?, Becoming a Worker, edited by K. Borman and J. Reisman, Norwood, NJ: Ablex, pp. 90-115. 
Hotz, V., Xu, T., Tienda, M. \& Ahituv, A. (2002), 'Are there returns to the wages of young men from working while in school?', Review of Economics and Statistics 84, 221-236.

Kalenkoski, C. \& Pabilonia, S. (2010), 'Parental transfers, student achievement, and the labor supply of college students', Journal of Population Economics 23, 469-496.

Kramarz, F. \& Skans, O. N. (2007), With a little help from my...parents? family networks and youth labor market entry. Mimeo, CREST, Paris.

Light, A. (1999), 'High school employment, high school curriculum, and post-school wages', Economics of Education Review 18, 291-309.

Lillydahl, J. (1990), 'Academic achievement and part-time employment of high-school students', Journal of Economic Education 21, 307-316.

Marsh, H. (1991), 'Employment during high school: Character building or a subversion of academic goals?', Sociology of Education 64, 172-189.

Meyer, R. \& Wise, D. (1982), High School Preparation and Early Labor Force Experience, Youth Labor Market Problem: Its Nature, Causes and Consequences. Chicago: University of Chicago Press.

Montmarquette, C., Viennot-Briot, N. \& Dagenais, M. (2007), 'Dropout, school performance, and working while in school', Review of Economics and Statistics 89, 752-760.

Oettinger, S. (1999), 'Does high school employment affect high school academic performance?', Industrial and Labor Relations Review 53, 136-151.

Rothstein, D. (2007), 'High school employment and youths academic achievement', The Journal of Human Resources 42, 194-213.

Ruhm, C. (1997), 'Is high school employment consumption or investment?', Journal of Labor Economics 15, 725-776.

Schill, W., McCartin, R. \& Meyer, K. (1985), 'Youth employment: Its relationship to academic and family variables', Journal of Vocational Behaviour 26, 155-163.

Steel, L. (1991), 'Early work experience among white and non-white youth', Youth and Society 22, 419-447.

Steinberg, L., Greenberger, E., Garduque, L. \& McAuliffe, S. (1982), 'High school students in the labor force: Some costs and benefits to schooling and learning', Educational Evaluation and Policy Analysis 4, 363-372. 
Stinebrickner, R. \& Stinebrickner, T. (2003), 'Working during school and academic performance', Journal of Labor Economics 21, 473-491.

Tyler, J. (2003), 'Using state child labor laws to identify the effect of school-year work on high school achievement', Journal of Labor Economics 21, 381-408. 